\title{
The Application of Chinese Elements in the Product Design
}

\author{
Xiaoqing Wu, Jicheng Xie \& Yang Mao \\ Tianjin Polytechnic University, Tianjin 300160, China \\ E-mail: wuxiaoqing1001@163.com
}

\begin{abstract}
The 21 st century will see the design competition in the market with cultural contest right behind it. A 5,000-year history civilization has left many Chinese elements to the modern China. It is worth considering as to how and where the precious cultural heritage can be melt into the modern life. I think a designer should make an in-depth understanding and application of traditional cultural elements after giving a profound study to Chinese culture and seizing its essence. He or she should pay attention to the world cultural exchanges and truly convey the spirit of China. He should never do any simple patchwork. I think those are essential to a successful product design that can display Chinese elements.
\end{abstract}

Keywords: Chinese culture, Chinese elements, Product design

\section{Introduction}

This text attempts to explore the product design from the perspective of the design elements which embodies the Chinese elements. As a Chinese future designer, facing the booming Chinese cause of design, he or she should open a field of design with Chinese features when connecting with the world, and put the Chinese culture into the modern product design.

\section{What are Chinese elements}

When talking about Chinese elements, either natives or foreigners will blurt out many living examples. Chinese elements are displayed in traditional culture, such as, Chinese painting, calligraphy, seal carving, Beijing Opera masks, cloisonne, Chinese japans, Chinese knots, shadow play, martial arts, tea, Chinese medicine; in religion or mythology, e.g. Guanyin, Rulai Buddha, Chinese Loong, and Qinlin; and in architecture, such as, the Imperial Palace, the Great Wall, Dunhuang fresco, Suzhou gardens, temples, Huabiao, Paifang, kiosks, and wells; in such costume of unique style of China as the emperor's crown, the Queen' phoenix coronet, silk brocade, Qipao, Tang Costume, sun yatsen's uniform, Dudou, embroidered shoes, tiger head shoes, Douli. Even the Yangtze River, Yellow River, Mount Huangshan, Mount Everest and other natural scenes, as well as Chinese pandas and Baiqitun fish are all unique elements.

Are Chinese elements the only forms expressed by these specific symbols? In fact, as early as in ancient times the correct answer was already given. Chinese philosophy was almost perfect even in the Spring and Autumn Period. It stresses the impartial Doctrine of the Mean. In the course of seeking Dao, the interaction and balance is adjusted between Heaven and man, body and mind. Nature takes its course. The limited life can realize its immortal significance. Great happiness can be achieved by self-transcendence over existence and non-existence. That is Chinese Yuan and Su. Yuan is the initial. And Su refers to the silk without being dyed. Chinese elements are profound and have broad meanings with prominent features of strong harmony and the expressions of images of man and nature.

\section{Chinese elements and Chinese culture}

Culture is strong enough to affect or even control the people's life though it is invisible. Chinese culture is the crystallization of Chinese civilization of several thousand years. In a new background of economic era, it has become a strong fulcrum to the commercial vitality. Nowadays more and more Chinese enterprises have begun to adopt the elements of Chinese culture while making sale promotion in the world and have already achieved a lot.

Geely Automobile attracted a large number of visitors by performance with the authentic Beijing Opera masks at Frankfurt Auto Show. Li-ning sports shoes drew the inspiration from the Zhaozhou Bridge and integrated the history and culture of the Chinese nation with the modern technology successfully in the product design, which is favored by numerous consumers. The identifier of shadow boxing in Beijing's bid for Olympic Games and the identifier of Chinese seal for Beijing 2008 Olympic Games both reflect that Chinese elements have brought inspiration to the field of design. In the background of Chinese traditional culture, more and more Chinese elements are applied into many fields of industrial product design, plane design, and costume design.

People have come to realize the importance of the Chinese elements. They have started to attach importance to using it and even to shouldering the mission of the rejuvenating the Chinese elements. Chinese culture is the core of Chinese 
civilization while the Chinese elements are the basic respect of the Chinese culture.

When more and more Chinese enterprises make for the international market, when the growing proportion of the Chinese products occupy the world, when China is getting closer and closer with the vast stage of the world, how to display the Chinese culture is not a question for the enterprises themselves because what they have shown about the Chinese elements is actually the synonyms of the images of China and Chinese products. From the design perspective, the world needs China for China's cultural heritage is a very rich resource bank to the world design and creativity.

\section{Chinese elements and product design}

The profound Chinese culture reveals the relationship between man and nature and guides the direction of development for the modern design.

How to apply these objective laws that has arrived for thousands of years to today's modern product design and how to integrate Chinese culture, Chinese elements into the product design are the topics that are worth deep thinking and researching.

The connotation of design is actually the culture. Design is not just a visual art. It is multi-disciplinary and needs much knowledge of different layers. Thus it is important for designers to get cultural accumulation in daily life. Design serves the reality so the application of Chinese elements should be acclimated to the trend of development on the basis of traditional Chinese culture. It can not do without the support of culture. Therefore, how to embody the culture in the design and how to cleverly integrate Chinese elements into the design will depend on a designer's background of knowledge and his or her capability of understanding the culture.

To better integrate Chinese culture and Chinese elements into the product design, first of all, a designer must deeply study the Chinese culture and be able to seize the essence of Chinese culture. Great China has owned a 5,000-year heritage of the Chinese culture, and a person can not understand all the wonders of it in a whole life. Chinese culture has left with us a great wealth and contains incalculable strength and potential so far. A Chinese designer must understand Chinese culture. However just having book knowledge and knowing history are far enough. A designer must be good at grasping the cultural essence of the modern design, and fully understand it. He or she can not be in the too much pursuit of culture while detach from the reality, or he or she can not completely be addicted to the reality without cultural knowledge as foil.

Secondly, when studying Chinese culture to seize the essence of the Chinese culture, we should pay much attention to the cultural exchanges. Applying the Chinese culture and adopt the advanced concepts into the modern product design, we can make the design cause to a new height.

Thirdly, integrating Chinese culture into the modern product design does not simply mean to draw the patterns with traditional features on the surface of the products. What is integrated into the product is spiritual civilization and cultural emotion rather than culture itself. Taking the products as carriers to give a natural expression of the cultural connotation set in products is exactly the embodiment of the third value - the spiritual value, which is above the economic and aesthetic values of products. What belongs to China is not historical. However it must be profound and can reflect and spread Chinese culture and Chinese spirits.

Finally, the application of Chinese elements in the design should not be deliberately emphasized, in particular, not put the cart before the horse. Chinese elements are not a panacea. Some symbols can be used, but it is not necessary to give eisegesis for symbol's sake. A Chinese element in product can not be deliberately sought or even be labeled on any surface. It should be a natural emotional outpouring of the designer after he or she gives a full understanding of the national culture. Thought Chinese elements are charm and rich in connotation, they need properly integrating and innovating. We must use Chinese elements to truly convey the Chinese spirit. It is not a simple patchwork. Chinese culture is like an inexhaustible old well and no one can know how deep it is. Symbols and superficial Chinese elements can not fully reflect the profoundness of the traditional culture and can not bring the genuine soul to the products.

Giving a profound study of Chinese culture and seizing the essence of Chinese culture, emphasizing the exchanges with other world cultures, stressing the Chinese spirit expressed by colors, patterns and other forms not only in the apparent products by also in the whole process of production, consumption and use, I think, are the means by which Chinese culture is integrated into the modern product design.

\section{Epilogue}

21 century will see the design competition right in the market. However it is the cultural contest that is behind the design competition. So we should broaden our mind and make our own judgment and expressions on the basis of deeply understanding the profound Chinese culture. Only by exploring our own culture can we go further in the creative economy.

As far as the design is concerned, aside from Chinese elements, it should agree with the actual development and the reception psychology of the masses, inherit, stress and develop Chinese culture. And Chinese product design will also 
be brilliant in the world.

\section{References}

Liu, Hongzhuang. and Qiao, Qingju. (2000.05). Notes to the Analects • Mencius. Huaxia Publishing House.

Guo, Jianqing. (2005). Brief Introduction to Chinese Culture. Shanghai Jiaotong University Press. 01

Liu, Jingwei. (2001). Brief Introduction to Traditional Chinese Culture. China Dadi Publishing House. 08

He, Lewei. (2006). Chinese Discovery-Artistic Taste. China Chang'an Publishing House. 07

Xun, Shenglan. (2002). Succeed to the folk art. Art and Design. 06 